\title{
Information and Announcements
}

\section{Science Academies' Refresher Course on Experimental Biology}

\author{
19 -31 December 2012
}

Sponsored by

Indian Academy of Sciences, Bangalore

Indian National Science Academy, New Delhi

The National Academy of Sciences, India, Allahabad

In collaboration with

Department of Biological Sciences, Indian Institute of Science Education and Research, Kolkata

A Refresher Course in Experimental Biology for college and university teachers will be organized at the Department of Biological Sciences, Indian Institute of Science Education and Research, Kolkata at Mohanpur, Nadia, West Bengal during 19-31 December 2012.

The Course will consist of stimulating experiments in different branches of biological sciences covering diverse techniques in cell biology, biochemistry, immunology, molecular biology and animal behaviour. The hands-on experiments would be accompanied by special lectures by eminent scientists in these fields. The focus of this Course is to acquaint the participants with novel avenues for exposing the students from various disciplines in biology at the undergraduate level to a variety of exciting topics in experimental biology.

Teachers who wish to participate in this Course should submit their brief curriculum vitae (including name, date of birth, gender, educational qualification with marks obtained, teaching experience, courses taught, postal and email addresses, phone numbers, etc., together with a brief statement as to why they would like to attend the course and its utility for their teaching).

Selected candidates will be provided local hospitality and round trip actual of bus/train fare (3-tier AC) by the shortest route. The applications may be sent by email to: Dr Partho Sarothi Ray, Course Coordinator, Department of Biological Sciences, Indian Institute of Science Education and Research Kolkata, Mohanpur, Nadia 741 252, West Bengal. Tel.: 03473-279224; Email: psray@iiserkol.ac.in

Last date for the receipt of application: 28 October 2012 